\title{
PENGEMBANGAN KUESIONER UNTUK MENGEVALUASI USABILITAS E-LEARNING
}

\author{
Amalia Kiswandari ${ }^{1}$ Rini Dharmastiti ${ }^{1}$ Andi Rahadiyan Wijaya ${ }^{1}$ \\ ${ }^{1}$ Jurusan Teknik Mesin dan Indsutri, Fakultas Teknik, \\ Universitas Gadjah Mada \\ email: amaliakiswandari@gmail.com, rini@ugm.ac.id, andi.rw@gmail.com
}

\begin{abstract}
ABSTRAK
Desain tampilan (interface) e-learning terkadang dipandang hanya sebagai suatu pilihan. Namun, sebenarnya tampilan merupakan alat utama yang berperan dalam mengarahkan pengguna pada pembelajaran menggunakan e-learning karena mewadahi semua elemen dalam kesatuan e-learning. Usabilitas adalah alat yang dapat mengukur interaksi yang efektif antara pengguna dan tampilan untuk mencapai tujuan yang spesifik. Kuesioner merupakan alat ukur yang praktis, efisien, dan paling banyak digunakan untuk evaluasi usabilitas. Namun, belum ada kuesioner khusus di Indonesia yang dapat mengevaluasi masalah usabilitas e-learning secara umum.
\end{abstract}

Tujuan dari penelitian ini adalah mengembangkan alat ukur kuesioner yang dapat menangkap masalah usabilitas pada e-learning, mengetahui atribut-atribut pertanyaan usabilitas yang paling berpengaruh terhadap evaluasi usabilitas studi kasus $e$-learning, dan mengevaluasi masalah usabilitas pada studi kasus beberapa $e$ learning dengan kuesioner yang telah dikembangkan. Objek penelitian ini adalah $e$ learning yang dikembangkan Universitas Gadjah Mada, yaitu eLisa, Sintesis (Fakultas Ekonomika dan Bisnis), Gamel (Fakultas Kedokteran), dan Papirus (Jurusan Teknik Elektro dan Teknologi Informasi). Sampel sebanyak 317 responden.

Hasil dari penelitian ini adalah kuesioner valid dan reliable, serta didapatkan 14 dimensi usabilitas dengan 56 variabel pertanyaan dari hasil analisis faktor. Kuesioner ini memiliki konsistensi dan relevansi antara permasalahan yang ada pada pertanyaan terbuka dengan tertutup dilihat dari nilai mean merit usabilitasnya. Hasil perbandingan empat e-learning adalah peringkat yang konsisten antara rata-rata nilai merit 56 variabel pertanyaan pada bagian isi dengan 5 variabel pertanyaan pada bagian kesimpulan. Hasil perbandingan dengan kuesioner lain menunjukkan bahwa kuesioner lebih efektif karena dapat mengungkap 73,21\% dari masalah yang ada pada eLisa dan lebih spesifik mengevaluasi suatu permasalahan usabilitas.

Penelitian ini masih dapat dikembangkan dan disempurnakan dari objek penelitian dari e-learning yang lebih general dengan gabungan responden dari beberapa negara untuk membuktikan hubungan karakteristik pengguna dari segi preferensi, budaya, dan bahasa yang mempengaruhi evaluasi setiap individu terhadap usabilitas suatu e-elarning.

Kata Kuci: kuesioner, evaluasi, usabilitas, e-learning, analisis faktor. 


\title{
QUESTIONNAIRE DEVELOPMENT TO EVALUATE E-LEARNING USABILITY
}

\begin{abstract}
Interface design of e-learning sometimes people see only as a choice, not the main point. But, the basic thing about interface is it the main tool that have function to give user direction about how is using e-learning because it covers all element in e-learning. Usability is the tool that can measure the effective interaction between user and interface to achieve specific purpose. Questionnaire is a tool that practical, efficient and the most using tool to evaluate the usability. But, there is not yet a specific questionnaire in Indonesia that can evaluate usability of e-learning in general.

The purpose of this study is to develop a measuring tool which is questionnaire that can capture usability problems in e-learning, know the usability questions attributes that become the most influence on the evaluation of the usability case studies in e-learning, and evaluate the problem of usability in the case study with the questionnaires which have been developed. The object of this study is an e-learning developed by the University of Gadjah Mada, namely eLisa, Synthesis (Faculty of Economics and Business), Gamel (Faculty of Medicine), and Papyrus (Department of Electrical Engineering and Information Technology). A sample of 317 respondents.

The results of this study are valid and reliable questionnaire, and obtained 14 usability dimensions with 56 variables question from factor analysis result. This questionnaire has the consistency and relevance with the problems that reflected in open-ended questions, covered views from the mean value of merit usability. The comparison of four e-learning is a consistent ratings between the average value of variable merit 56 questions on the contents of the variable 5 questions in the concluding section. The result of comparisons with other questionnaires showed that the questionnaire is more effective because it can cover $73.21 \%$ of the existing problems in a more specific eLisa and evaluate a problem of usability.

This research can still be developed and refined from research object of e-learning are more general by a combination of respondents from several countries to prove the relationship of user characteristics in terms of preference, culture, and language affect the evaluation of each individual to the usabiltity of e-elarning.
\end{abstract}

Passwords : questionnaire, evaluation, usability, e-learning, factor analysis 


\section{PENDAHULUAN}

Peningkatan kebutuhan, ekspansi teknologi, perubahan secara radikal dalam tugas pelajaran, dan tantangan yang semakin signifikan membuat aplikasi $e$ learning berkembang dengan semakin pesat (Qureshi dan Irfan, 2009). Tampilan (interface) sebagai perantara antara manusia dan komputer untuk berinteraksi (Edwards, 2011) adalah elemen paling penting yang dapat mewadahi semua elemen tersebut dalam kesatuan e-learning (Triacca, dkk., 2004).

Terkait pada tampilan, usabilitas suatu e-learning sangat penting untuk pembelajaran online yang efektif [4]. Usabilitas dilakukan untuk mendeteksi sebagian besar permasalahan, kendala, dan gangguan pengguna saat berinteraksi dengan aplikasi web berdasarkan tingkat efektif, efisien, dan kepuasan (SO 942111, 1995). Usabilitas dilakukan dengan memperhitungkan karakteristik dari pengguna, seperti preferensi, bahasa, dan budaya dengan konteks penggunaan, seperti aksesibilitas mudah dan luminositas yang baik dari lingkungan, sehingga untuk setiap e-learning dengan karakteristik pengguna yang berbeda-beda, membutuhkan penilaian usabilitas yang berbeda-beda pula untuk mengevaluasi permasalahan yang dialami pengguna pada interface (tampilan) suatu e-learning.

Kuesioner merupakan alat evaluasi yang paling banyak digunakan (Bernérus, dan Zhang, 2010) karena memiliki keunggulan, yaitu efisiensi, pada segi waktu, efektivitas biaya, kemudahan aplikasi, dan keahlian (Gray, dan Salzman, 1998). Kuesioner terbukti efisien dengan pertanyaan pertanyaan tertutup, namun akan sangat sulit menemukan masalah pada pertanyaan tertutup, seperti penelitian Kiswandari yang hanya menemukan masalah usabilitas dari pertanyaan terbuka kuesioner.
Di Indonesia, belum ada alat ukur dalam mengevaluasi usabilitas untuk $e$ learning secara general. Dengan demikian, diperlukan suatu penelitian mengenai pengembangan alat ukur usabilitas elearning. Tidak hanya yang dapat sesuai dengan kebutuhan pengguna e-learning di Indonesia, namun juga dapat menangkap permasalahan usabilitas dengan bentuk pertanyaan tertutu, sehingga lebih praktis.

\section{MATERI DAN METODE}

Objek penelitian ini adalah empat $e$ learning yang dimiliki Universitas Gadjah Mada, yaitu eLisa (Universitas Gadjah Mada), Sintesis (Fakultas Ekonomika dan Bisnis), Gamel (Fakultas Kedokteran), dan Papirus (Jurusan Teknik Elektro dan Teknik Informasi). Terdapat perbedaan antara setiap e-learning, yaitu pada tampilan dan juga fitur-fitur khas yang dimiliki. Lampiran 2 menunjukkan fiturfitur tambahan yang dimiliki e-learning. Untuk melihat efektivitas dan efesiensi kuesioner yang dikembangkan, dilakukan perbandingan pada objek penelitian eLisa.

Pengambilan data melalui 2 cara, yaitu langsung melalui lembaran kertas kepada masing-masing subjek penelitian di Universitas Gadjah Mada dan pengisian tidak langsung melalui google docs (docs.google.com). Subjek penelitian adalah mahasiswa Universitas Gadjah Mada tahun ajaran 2013/2014 angkatan 2009-2013.

Data didapatkan dari 317 responden dari mahasiswa UGM dengan 28,5\% respon kuesioner online dan $83,6 \%$ respon kuesioner.

Pada bagian awal kuesioner, terdapat beberapa identitas yang dapat disimpulkan dari 317 responden, yang terdiri dari 3 Fakultas, yaitu Teknik, Kedokteran, dan Ekonomika dan Bisnis seperti yang terlihat pada Gambar 1 dan proporsi pada Tabel 1. 


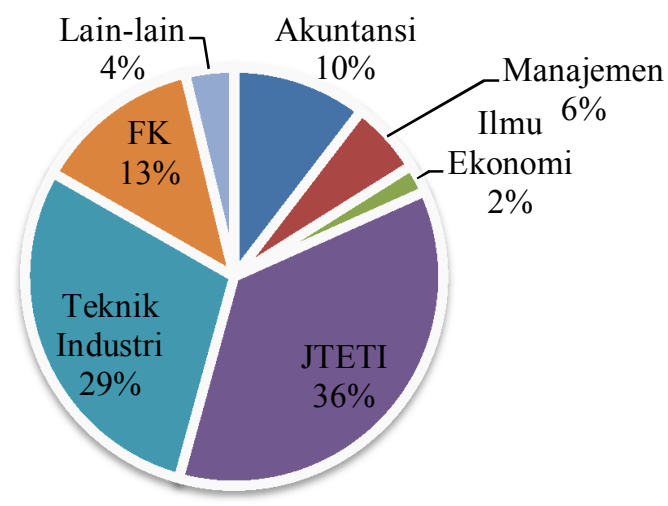

\begin{tabular}{|l|r|r|r|r|}
\hline \multirow{4}{*}{$\begin{array}{l}\text { Teknologi } \\
\text { Informasi }\end{array}$} & 2010 & 61 & 0,015 & 5 \\
\cline { 2 - 5 } & 2011 & 72 & 0,0 & 6 \\
\cline { 2 - 5 } & 2012 & 62 & 0,015 & 5 \\
\hline \multirow{3}{*}{$\begin{array}{l}\text { Teknik } \\
\text { Industri }\end{array}$} & 2013 & 52 & 0,013 & 5 \\
\cline { 2 - 5 } & 2010 & 140 & 0,035 & 12 \\
\cline { 2 - 5 } & 2011 & 128 & 0,032 & 11 \\
\hline & 2012 & 135 & 0,034 & 12 \\
\hline & & 140 & 0,035 & 12 \\
\hline
\end{tabular}

Gambar 1. Background Pendidikan Responden

Tabel 1. Perhitungan Jumlah Sampel Kuesioner Awal

\begin{tabular}{|c|c|c|c|c|}
\hline Jurusan & Angkatan & Jumlah & Proporsi & Sampel \\
\hline \multirow{4}{*}{$\begin{array}{l}\text { Pendidikan } \\
\text { Dokter }\end{array}$} & 2010 & 281 & 0,071 & 23 \\
\hline & 2011 & 301 & 0,076 & 25 \\
\hline & 2012 & 228 & 0,057 & 19 \\
\hline & 2013 & 220 & 0,055 & 19 \\
\hline \multirow{4}{*}{ Akuntansi } & 2010 & 129 & 0,032 & 11 \\
\hline & 2011 & 188 & 0047 & 16 \\
\hline & 2012 & 167 & 0042 & 14 \\
\hline & 2013 & 122 & 0,030 & 11 \\
\hline \multirow{4}{*}{$\begin{array}{l}\text { Ilmu } \\
\text { Ekonomi }\end{array}$} & 2010 & 64 & 0,016 & 6 \\
\hline & 2011 & 82 & 0,020 & 7 \\
\hline & 2012 & 85 & 0,021 & 7 \\
\hline & 2013 & 75 & 0,018 & 7 \\
\hline \multirow{4}{*}{ Manajemen } & 2010 & 122 & 0,030 & 11 \\
\hline & 2011 & 166 & 0,041 & 14 \\
\hline & 2012 & 137 & 0,034 & 12 \\
\hline & 2013 & 103 & 0,026 & 9 \\
\hline \multirow{4}{*}{$\begin{array}{l}\text { Teknik } \\
\text { Elektro }\end{array}$} & 2010 & 93 & 0,023 & 8 \\
\hline & 2011 & 125 & 0,031 & 11 \\
\hline & 2012 & 118 & 0,029 & 10 \\
\hline & 2013 & 103 & 0,026 & 9 \\
\hline
\end{tabular}

Metode pengolahan kuesioner menggunakan Eksploratory Factor Analysis (EFA). EFA adalah suatu metode untuk menganalisis sejumlah observasi yang dipandang dari sisi interkorelasinya untuk mendapatkan variasi-variasi yang nampak dalam observasi berdasarkan atas sejumlah kategori dasar yang jumlahnya lebih sedikit dari yang nampak. Dengan analisis faktor, validitas suatu kuesioner dapat diuji (Bornstedt, 1977).

Kemudian dianalisis faktor-faktor yang terbentuk dan dilihat kesesuaian dengan dimensi usabilitas dan diuji nilai reliabilitas dan validitas. Tahap selnjutnya adalah membandingkan konsistensi hasil pertanyan tertutup dan terbuka antar elearng. Setelah terbukti konsisten, $e$ learning dapat diurutkan berdasarkan mean usabilitasnya.

Kuesioner yang sudah terbukti valid, reliabel, dan konsisten ini kemudian dibandingkan dengan kuesioner lain untuk dianalisis tingkat efektivitas dan efisieni dari kuesioner.

\section{HASIL DAN PEMBAHASAN}

Hasil pengembangan kuesioner awal terdiri dari 56 variabel pertanyaan dan 17 dimensi usabilitas. Hasil dari uji validitas terdapat pada Tabel 2 dan dengan hasil yang menunjukkan bahwa hampir semua 
(The Indonesian Journal of Ergonomic)

data memiliki $p$-value $<0,05$, sehingga pertanyaan-pertanyaan tersebut valid.

Setelah divalidasi, 56 pertanyaan pertanyaan tertutup diuji nilai reliabilitasnya dengan pendekatan Cronbach's alpha. Untuk pengujian terbukti secara keseluruhan bahwa kuesioner memiliki reliabilitas yang tinggi. Untuk penghitungan tiap dimensi, dimensi 15, 16, dan 17 memiliki nilai yang kecil dan setelah dihitung plot PCA seperti ada Gambar 2. Didapatkan hasil pesebaran berdaarkan e-learning, sehingga memiliki nilai reliabilitas yang kecil.

Hasil uji asumsi awal analisis faktor, yaitu uji multikolinearitas menunjukkan nilai $\mathrm{KMO}>0,5$ dan signifikansi $<0,05$ dan disimpulakan memenuhi asumsi awal. Dari hasil Exploratory Factor Analysis didapatkan 14 faktor dan dianalisis terdapat 10 dimensi usabilitas baru dari variabelvariabel pertanyaan yang ada pada setiap faktor yang ditunjukkan pada Tabel 2 . Kuesioner ini kemudian diuji validitas dan reliabilitasnya pada 66 responden dan terbukti memenuhi dua uji ini.

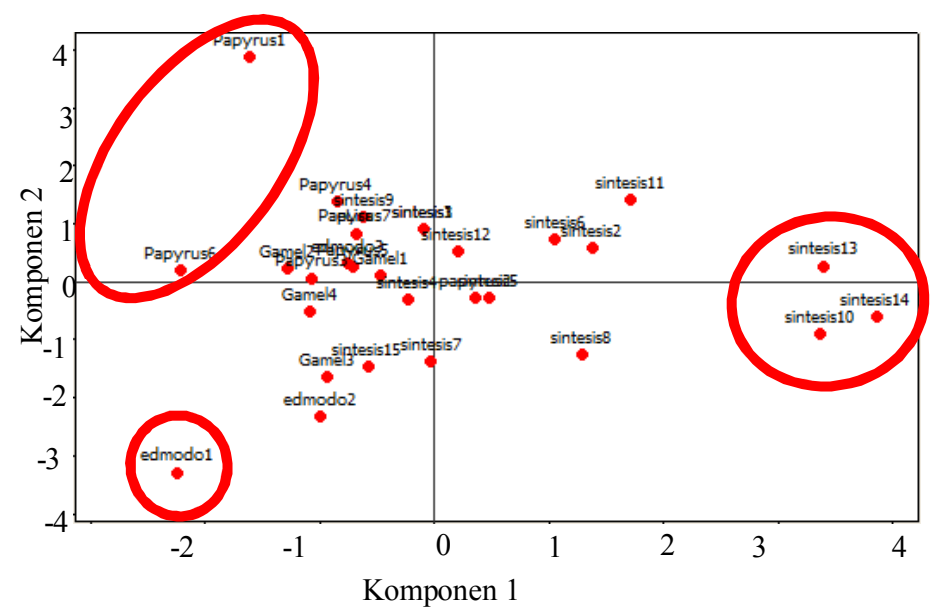

Gambar 2. Plot PCA Dimensi 15, 16, dan 17
Vol.2, No.1 : 1 Januari-Juni 2016

Tabel 2. Hasil Analisis Faktor dan Penamaan Dimensi Usabilitas

\begin{tabular}{|c|c|}
\hline No. & Dimensi \\
\hline 1 & $\begin{array}{l}\text { Visibilitas dari elemen-elemen pada } \\
\text { sistem }\end{array}$ \\
\hline 2 & $\begin{array}{l}\text { Kesesuaian sistem dengan kebutuhan } \\
\text { pengguna }\end{array}$ \\
\hline 3 & $\begin{array}{l}\text { Relevansi dan Kejelasan Materi pada } \\
\text { e-learning dengan Tingkat } \\
\text { kedalaman materi di kelas }\end{array}$ \\
\hline 4 & Opsi bantuan dan dokumentasi \\
\hline 5 & $\begin{array}{l}\text { Dukungan dalam Pembelajaran di } \\
\text { Kelas }\end{array}$ \\
\hline 6 & Notifikasi Sistem yang Efektif \\
\hline 7 & $\begin{array}{l}\text { Petunjuk Awal Penggunaan } E \text { - } \\
\text { learning bagi Pemula }\end{array}$ \\
\hline 8 & $\begin{array}{l}\text { Tingkat Keparahan Kesalahan (error) } \\
\text { pada Sistem dan Efektivitas Shortcut }\end{array}$ \\
\hline 9 & $\begin{array}{l}\text { Kontrol dan Kebebasan Pengguna } \\
\text { serta Konsistensi Sistem }\end{array}$ \\
\hline 10 & $\begin{array}{l}\text { Petunjuk perbaikan error dan } \\
\text { Tampilan E-learning yang Menarik }\end{array}$ \\
\hline 11 & $\begin{array}{l}\text { Navigasi Aplikasi, Pengaturan, dan } \\
\text { Struktur yang Simpel }\end{array}$ \\
\hline 12 & $\begin{array}{l}\text { Keaslian dan Minimalisme Desain } \\
\text { yang Efisien }\end{array}$ \\
\hline 13 & $\begin{array}{l}\text { Efisensi Konektivitas dengan } E \text { - } \\
\text { learning }\end{array}$ \\
\hline 14 & Warna Tampilan dari E-learning \\
\hline
\end{tabular}

Hasil pertanyaan tertutup baik dari 56 variabel pertanyaan maupun 5 pertanyaan pada bagian kesimpulan menunjukkan bahwa Gamel jauh lebih baik usabilitasnya dibandingkan dengan e-learning lainnya. Hal ini sesuai dengan yang didapatkan dari hasil 14 dimensi. Urutan semua e-learning sudah menunjukkan konsistensi, yaitu dengan nilai usabilitas paling baik adalah Gamel dan yang paling rendah adalah Sintesis.

Untuk perbandingan output pada eLisa pada pertanyaan tertutup, eLisa memiliki nilai usabilitas paling rendah untuk masalah notifikasi. Untuk Sintesis, masalah yang didapat dari pertanyaan 


\section{Jurnal Ergonomi Indonesia}

\section{(The Indonesian Journal of Ergonomic)}

terbuka terdapat pada bagian kecepatan server dalam mengakses e-learning. Namun, masalah ini hanya terjadi saat KRS, sedangkan pada proses pembelajaran, hal ini tidak terjadi karena e-learning tidak terlalu berat. Untuk masalah tampilan yang monoton bagian pertanyaan terbuka, memiliki konsistensi dengan hasil yang didapat pada pertanyaan terbuka, yaitu dengan nilai rendah pada dimensi 14 , yaitu warna tampilan e-learning.

Gamel yang ada pada peringkat pertama pada perhitungan output pertanyaan tertutup mempunyai kesesuaian dengan sedikitnya masalah yang ada pada Gamel. Masalah utama pada Gamel terdapat pada tampilan yang kurang menarik ada pada dimensi 14. Pada hasil pertanyaan tertutup, Gamel juga memiliki nilai usabilitas paling rendah pada dimensi yang sama.

Hasil pertanyaan tertutup dan pertanyaan terbuka menunjukkan terdapat hasil nilai merit paling rendah pada Papirus di dimensi ke-14 mengenai warna tampilan. Hal ini sesuai dengan hasil pertanyaan terbuka yang menunjukkan hasil yang sama, yaitu permasalahan pada tampilan yang monoton.

Hasil kuesioner pengembangan kemudian dibandingkan dengan kuesioner lain pada 10 parameter, yaitu objektif, objek penelitian, metode penyusun, kuesioner, reliabilitas, validitas, skala jawaban, waktu pengerjaan, jumlah pertanyaan, dimensi usabilitas, output pertanyaan tertutup, dan output pertanyaan terbuka. Hasilnya kuesioner unggul pada kriteria efektivitas dari masalah yang didapatkan pada hasil pertanyaan tertutup dan terbuka.

Perbandingan lanjutan dilakukan dengan kuesioner untuk mengevaluasi LPP UNS (Iftadi, 2008) dengan objek penelitian eLisa dengan hasil temuan masalah dari metode Thinking Aloud eLisa (Kiswandari,
2013) dan menghasilkan kesimpulan pada Tabel 2.

Tabel 3 menunjukkan bahwa kuesioner Kiswandari lebih efisien dengan rate pengerjaan yang dibutuhkan. Pada perbandingan dengan masalah yang dapat ditangkap, kuesioner Kiswandari lebih efektif karena dapat mengungkap 73,21\% dari masalah yang ada, sedangkan kuesioner Iftadi memiliki variabel pertanyaan masih bersifat umum, sehingga kurang spesifik menyasar pada suatu permasalahan dan ditunjukkan pada 45,5\% variabel mengungkap lebih dari satu permasalahan usabilitas. Hasil perbandingan ini adalah walaupun tingkat efisiensi pengerjaan kuesioner yang dikembangkan lebih rendah, namun sudah dapat sesuai dengan $73,21 \%$ masalah yang ada pada eLisa.

Hasil dari pengujian pengaruh background pendidikan terhadap jawaban akan usabilitas eLisa menunjukkan bahwa bahwa hampir semua dimensi mempunyai p-value $>0,05$ dengan hasil menolak $\mathrm{H}_{0}$. Dari hasil ini dapat dibuktikan bahwa perbedaan asal fakultas tidak mempengaruhi preferensi usabilitas suatu e-learning.

Tabel 3. Perbandingan Kuesioner

Kiswandari (2014) dan Iftadi (2008)

\begin{tabular}{|c|c|c|}
\hline Parameter & $\begin{array}{l}\text { Iftadi } \\
\text { (2008) }\end{array}$ & $\begin{array}{l}\text { Kiswandari } \\
\text { (2014) }\end{array}$ \\
\hline $\begin{array}{ll}\text { Jumlah } & \text { variabel } \\
\text { pertanyaan } & \end{array}$ & 14 & 56 \\
\hline $\begin{array}{lr}\text { Jumlah } & \text { masalah TA } \\
\text { yang } & \text { terungkap } \\
\text { dengan } & \text { variabel } \\
\text { pertanyaan } & \end{array}$ & 22 & 41 \\
\hline $\begin{array}{l}\text { Variabel pertanyaan } \\
\text { yang sesuai dengan } \\
\text { masalah TA }\end{array}$ & 10 & 30 \\
\hline Waktu pengerjaan & 5 menit & 15 menit \\
\hline Rate Pengerjaan & $\begin{array}{l}21,43 \\
\text { detik }\end{array}$ & 16 detik \\
\hline Reliabilitas & 0,894 & 0,928 \\
\hline
\end{tabular}




\section{SIMPULAN DAN SARAN}

Berdasarkan uraian dan hasil penelitian mengenai pengembangan alat ukur kuesioner untuk mengevaluasi usabilitas e-learning dapat ditarik kesimpulan sebagai berikut:

1. Pengembangan kuesioner baru hasil dari analisis faktor menghasilkan 56 variabel pertanyaan tertutup yang dibagi menjadi 14 faktor. Dari 14 faktor, terdapat 10 dimensi baru yang dikembangkan berdasarkan variabel-variabel pertanyaan yang terletak dalam satu faktor yang sama.

2. Terdapat konsistensi dan relevansi antara permasalahan yang ada pada pertanyaan terbuka dengan pertanyaan tertutup dilihat dari nilai mean merit usabilitasnya.

3. Hasil perbandingan empat e-learning adalah peringkat yang konsisten antara rata-rata nilai merit 56 variabel pertanyaan pada bagian isi dengan 5 variabel pertanyaan pada bagian kesimpulan. Peringkat dari e-learning dengan nilai usabilitas paling baik adalah Gamel, Papirus, eLisa, dan Sintesis.

4. Hasil perbandingan dengan kuesioner lain menunjukkan bahwa kuesioner lebih efektif karena dapat mengungkap $73,21 \%$ dari masalah yang ada pada eLisa.

Penelitian ini masih dapat dikembangkan dan disempurnakan dari objek penelitian dari e-learning yang lebih general dengan gabungan responden dari beberapa negara untuk membuktikan hubungan karakteristik pengguna dari segi preferensi, budaya, dan bahasa yang mempengaruhi evaluasi setiap individu terhadap usabilitas suatu e-elarning.

\section{DAFTAR PUSTAKA}

Bornstedt, G.W., 1977, Reliability and Validity in Attitude Measurement, G.F. Summers (Ed.), Kershaw Publishing Company, London.

Edwards, E., 2011, The Importance of Successful E-learning Interface Design, Allen Interaction. Bernérus, A. dan Zhang, J., 2010, A Peek at the Position of Pedagogical Aspects in Usability Evaluation of Elearning System, University of Gothenburg.

Gray, W.D. \& Salzman, M.C., 1998, Repairing Damaged Merchandise: A Rejoinder, Human-Computer Interaction, Vol. 13, No. 3, pp. 325335.

Iftadi, I., 2008, Pengembangan Kuisioner Usablitas E-learning, LPP UNS, Tesis Jurusan Teknik Mesin dan Industri, Universitas Gadjah Mada.

Kiswandari, A., 2013, Evaluasi Usabilitas eLisa dengan Metode Kuesioner dan Thinking aloud, Skripsi Jurusan Teknik Mesin dan Industri, Universitas Gadjah Mada.

ISO 9421-11, 1995, Ergonomic Requirements for Office Work with Visual Display Terminal (VDT's) Part 11 : Guidence on Usability, International Organization of Standarization.

Qureshi, S.A dan Irfan, M, 2009, Usability Evaluation of E-learning Applications, A Case Study of It's Learning From A Student's Perspective, Master Thesis Computer Science Thesis no: MCS-2009-15, University of Blekinge Tekniska Högskola.

Triacca, L., Bolchini, D., Botturi, L. dan Inversini, A., 2004, MiLE: Systematic Usability Evaluation for E-learning Web Applications, In L. Cantoni \& C. McLoughlin (Eds.), Proceedings of World Conference on Educational Multimedia, Hypermedia and Telecommunications, pp. 4398-4405.

Zaharias, P. \& Poulymenakou, A., 2006, Implementing Learner-Centered Design: The interplay between usability and instructional design 
ISSN Print : 1411 -951 X, ISSN Online : 20503-1716

Jurnal Ergonomi Indonesia

(The Indonesian Journal of Ergonomic)

Vol.2, No.1 : 1 Januari-Juni 2016

practices, Journal of Interactive

Technology and Smart Education, Vol 3 (2), pp. 87-100. 